\title{
ADDENDUM
}

https://doi.org/10.1038/s41467-019-10615-0

\section{Addendum: Precise tuning of gene expression levels in mammalian cells}

\author{
Yale S. Michaels (1) 1, Mike B. Barnkob (1) 2, Hector Barbosa1, Toni A. Baeumler', Mary K. Thompson (1) ${ }^{3}$, \\ Violaine Andre ${ }^{2}$, Huw Colin-York ${ }^{2}$, Marco Fritzsche ${ }^{2,4}$, Uzi Gileadi ${ }^{2}$, Hilary M. Sheppard ${ }^{5}$, David J.H.F. Knapp ${ }^{1}$, \\ Thomas A. Milne (i) ${ }^{6}$, Vincenzo Cerundolo ${ }^{2} \&$ Tudor A. Fulga ${ }^{1}$
}

Addendum to: Nature Communications https://doi.org/10.1038/s41467-019-08777-y, published online 18 February 2019.

Following re-sequencing of the miSFIT constructs used in the paper, two of the construct variants inserted into the 3'UTR of PD-1, namely ' $12 \mathrm{C}$ ' and ' $17 \mathrm{~A}, 18 \mathrm{G}$ ', have been found to contain additional insertions not present in the other construct variants. The data points corresponding to these constructs in Fig. 2c, f and Supplementary Fig. 9 are therefore no longer valid. However the overall conclusion that the miSFIT system allows step-wise control over gene expression levels remains unaffected by these errors. Updated versions of Fig. 2 and Supplementary Fig. 9 are presented below as Figs. 1 and 2 respectively.

Published online: 10 June 2019

Open Access This article is licensed under a Creative Commons Attribution 4.0 International License, which permits use, sharing, adaptation, distribution and reproduction in any medium or format, as long as you give appropriate credit to the original author(s) and the source, provide a link to the Creative Commons license, and indicate if changes were made. The images or other third party material in this article are included in the article's Creative Commons license, unless indicated otherwise in a credit line to the material. If material is not included in the article's Creative Commons license and your intended use is not permitted by statutory regulation or exceeds the permitted use, you will need to obtain permission directly from the copyright holder. To view a copy of this license, visit http://creativecommons.org/licenses/by/4.0/.
}

(C) The Author(s) 2019

\footnotetext{
${ }^{1}$ Weatherall Institute of Molecular Medicine, Radcliffe Department of Medicine, University of Oxford, Oxford OX3 9DS, UK. ${ }^{2}$ MRC Human Immunology Unit, Weatherall Institute of Molecular Medicine University of Oxford, Oxford OX3 9DS, UK. ${ }^{3}$ Department of Biochemistry, University of Oxford, Oxford OX1 3QU, UK. ${ }^{4}$ Kennedy Institute of Rheumatology, Nuffield Department of Orthopaedics, Rheumatology and Musculoskeletal Sciences, Oxford OX3 7FY, UK. ${ }^{5}$ School of Biological Sciences, University of Auckland, Auckland 1050, New Zealand. ${ }^{6}$ Weatherall Institute of Molecular Medicine, MRC Molecular Haematology Unit, NIHR Oxford Biomedical Research Centre Programme, University of Oxford, Oxford OX3 9DS, UK. Correspondence and requests for materials should be addressed to T.A.F. (email: tudor.fulga@imm.ox.ac.uk)
} 


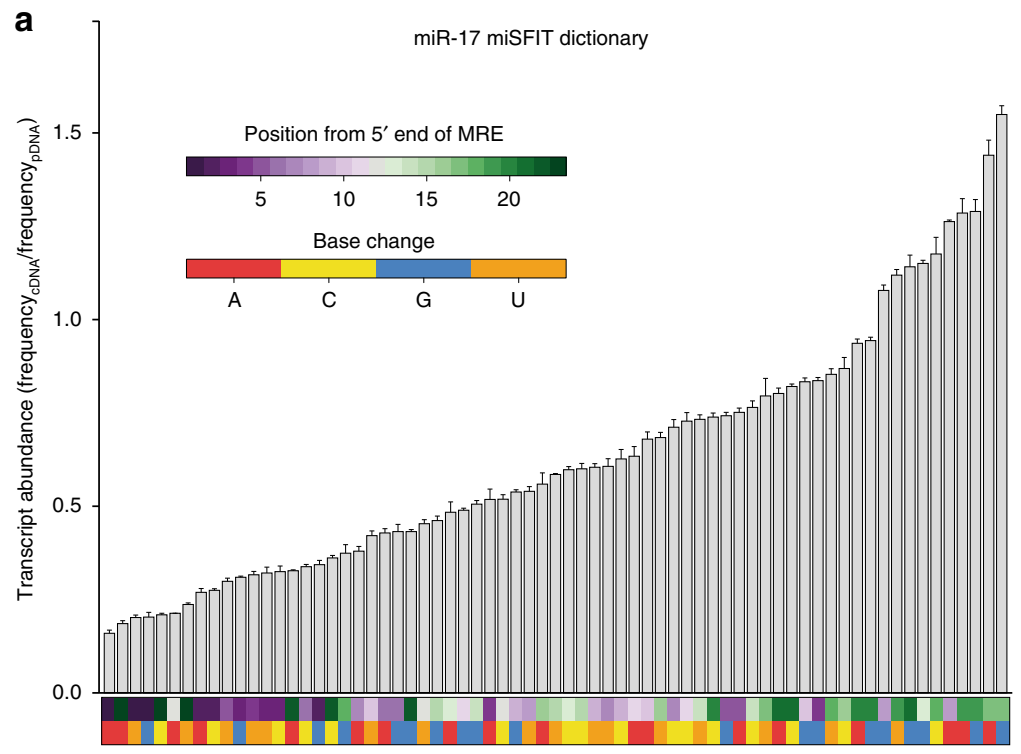

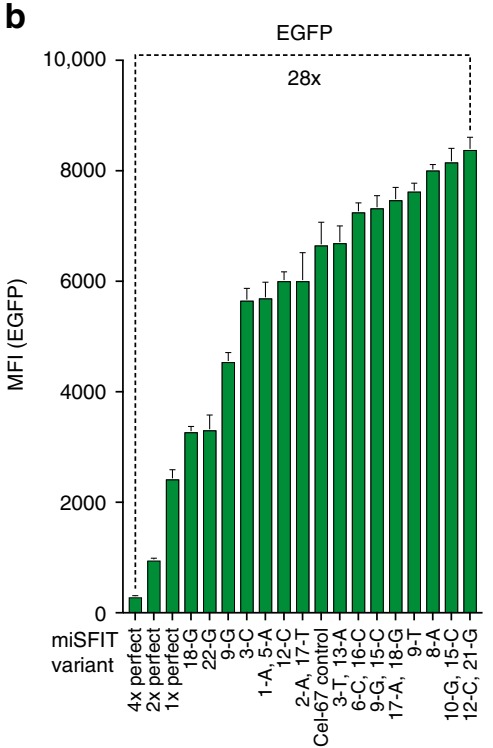

C
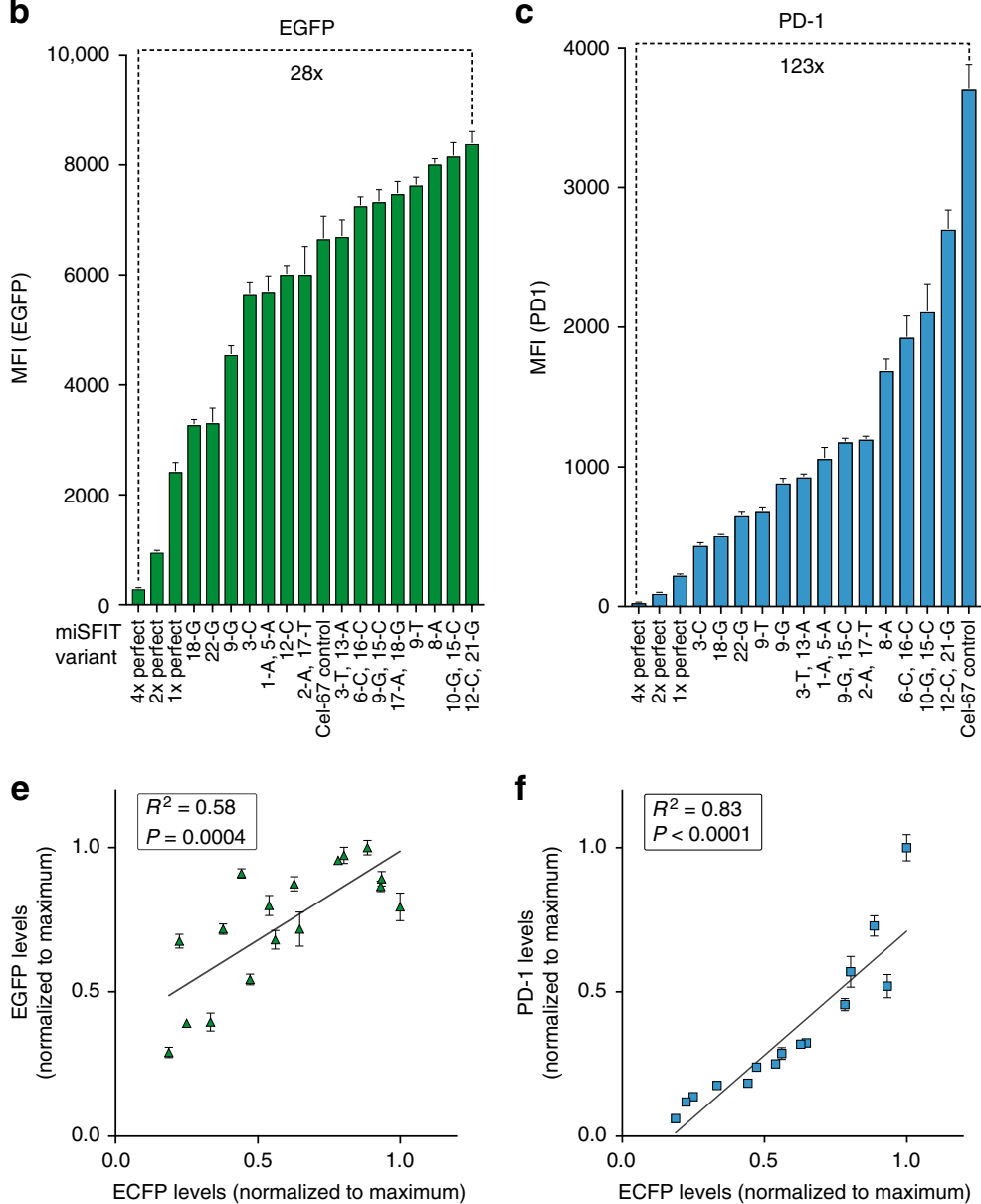

f

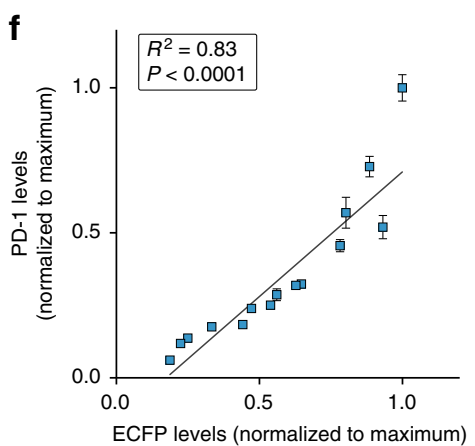

d

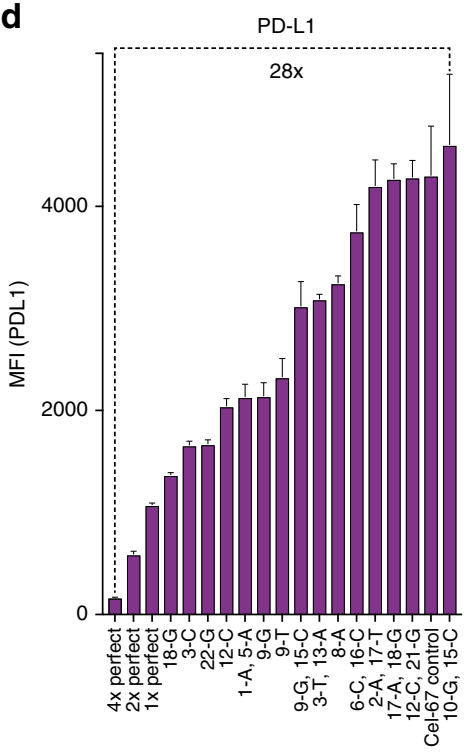

g

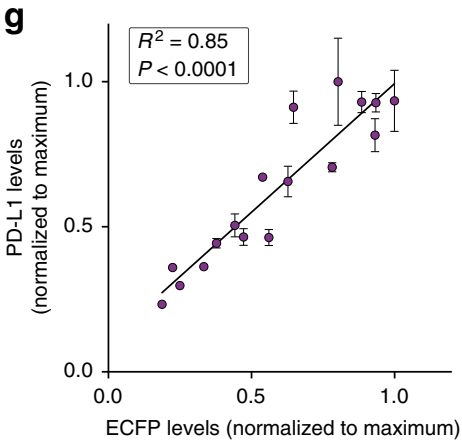

Fig. 1 

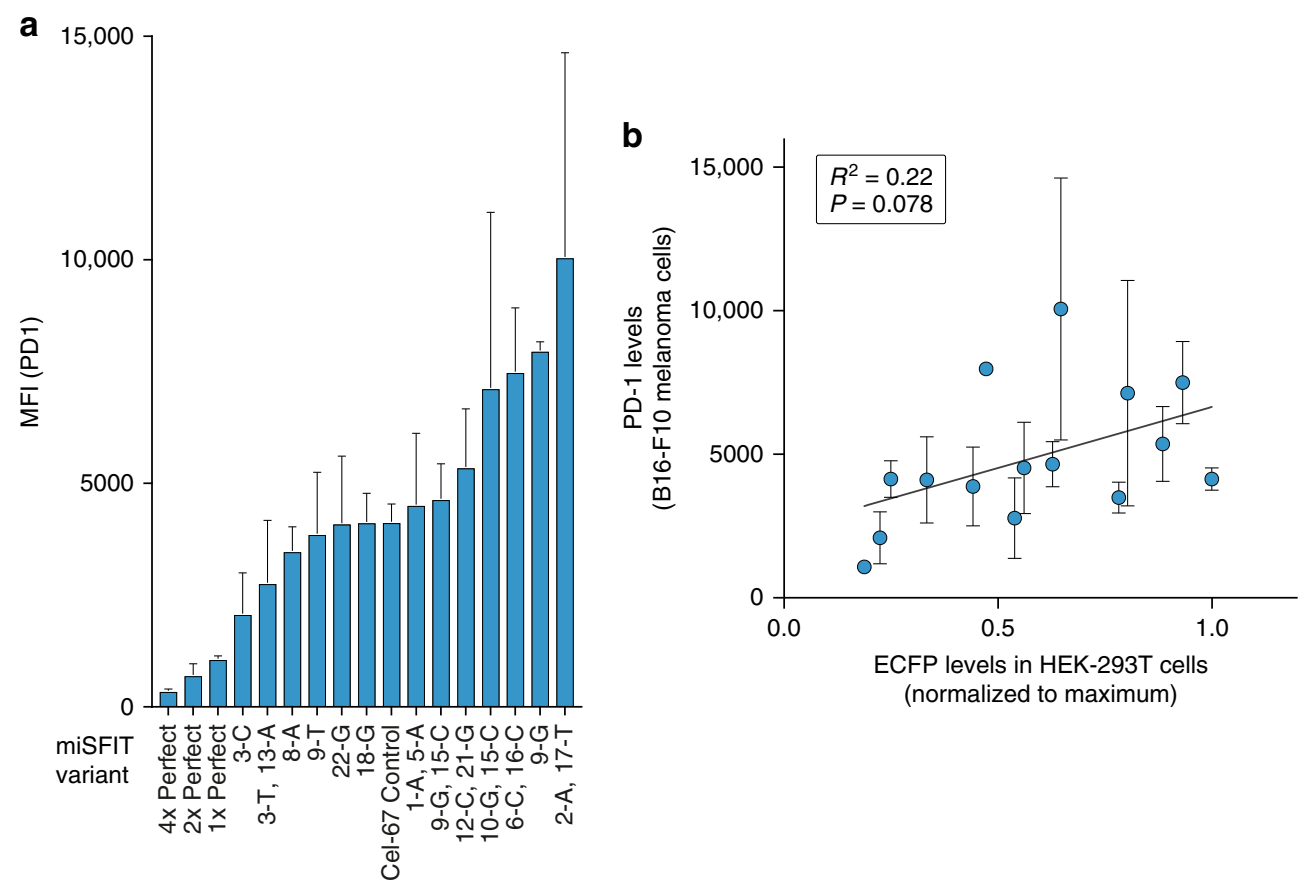

Fig. 2 